\title{
Academics In Motion: cultural encapsulation and feeling at home
}

\author{
ZERRIN G. TANDOGAN \\ Bilkent University
}

EMINE ONARAN INCIRLIOGLU

Bilkent University

In this article we explore the concept of "home" and transnational experiences among expatriate academics in a multicultural housing complex of a private university in Ankara, Turkey. The international academics employed by the university and the educators working in the International School that is also located on campus constitute a sizeable proportion of the residents in this housing complex. Although on-campus housing that comes with some degree of cultural encapsulation has considerable advantages for a group of expatriates, it also creates perplexities due to the distant location of the campus from the city center, the limited availability of social contact with the locals, and the "sterility" of the university environment. Based on indepth interviews with a small group of these expatriates, we present the quandaries of cultural encapsulation and feeling at home. [Turkey, transnationals, cosmopolitans, home, cultural encapsulation]

s transnational experiences are becoming increasingly
commonplace, the concept of home is also changing and
being redefined. ${ }^{1}$ Home is not necessarily fixed to a specific
location any longer for people in motion-the main actors of this
change. Although both transnationalism and home are ambiguous
and volatile concepts, and thus risky to use, they are appropriate
analytical tools for a discussion on "the cultural and social sig-
nificance of moving in space and the transnational communities"
(Olwig 1997:17) that emerge as a consequence of this mobility.
In the late 1990s, Portes, Guarnizo and Landolt maintained
that transnationalism was a truly original phenomenon unlike
other forms of international mobility due to its "high intensity of 
exchanges, the new modes of transacting, and the multiplication of activities that require cross-border travel and contacts on a sustained basis" (1999:227). Although it is clear that the movement of people globally is centuries old, the speed and the intensity of the communications between people regardless of their territorial residences is a consequence of the vast developments in communications and technology. Transnationalism is a postmodern condition which refers to multiple ties and interactions linking people or institutions across borders of nation states, which, according to Vertovec (1999:447), covers a wide range of relationships, structures, networks and social groupings. In this complex and multilayered postmodern context, the more people travel, the more they develop new webs of relations and coping strategies in new cultural environments. Here, migrants constitute the most studied group, as the multiplicity of their engagements in at least two nation-states, namely home and host, is a crucial element in the delineation of transnationalism (Schiller et al. 1992). Yet migrants are by no means the only transnationals who have "feet in two societies."

This paper is based on research among a group of international academics and educators who also have "feet in two societies."2 Contracted to teach in a private university and an International School $^{3}$ in Ankara, these academics, educators and teachers con-

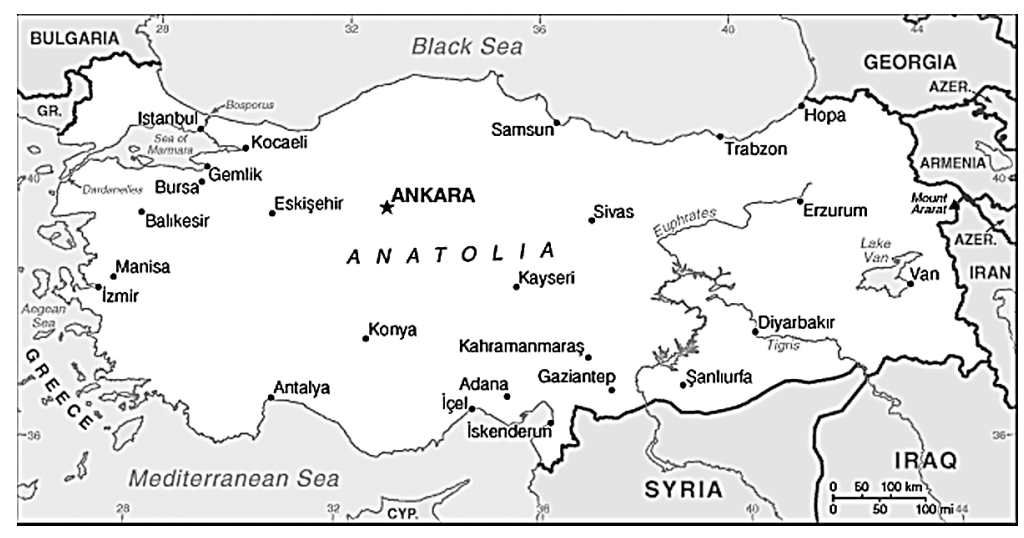

stitute the actors of our research. These expatriates operate in an international job market, seek job opportunities through international job fairs or Internet announcements, and they travel the world for short-term or long-term positions. We have produced information through indepth interviews and relied on informal networks for drawing our informants; eleven individuals belonging to nine households. We and conducted "friendly" interviews in order to explore the diverse intentions, experiences and purposes of people in motion. The group of people we present in this paper, like other transnationals, travel to and live in different cultural and social environments, establish their own networks in new settings, and maintain contact with their countries of origin. They are different from labor 
migrants in the sense that they usually do not move to other places merely for economic concerns but also with a desire of experiencing the Other. Traveling appears to be their lifestyle and diverse experiences seem to be their way of life. Because of the nature of their contractual work they spend relatively shorter periods of time in foreign countries.

The experiences of the transnationals who live in a university housing community will guide us to understand not only people in motion but also their diverse meanings of "home," "belonging," "identity" and "social exclusion." Vertovec urges us that "there is immediate need for more, in-depth and comparative empirical studies of transnational human mobility, communication, social ties, channels and flows of money, commodities, information and images — as well as how these phenomena are made use of' (1999: 456). Studies on transnationalism usually take a Western rhetorical and theoretical perspective as prevalent in migration studies. In our study however, we portray an experience that is different from that of non-European labor migrants, refugees, or people living in the "diaspora." Unlike the mainstream studies of transnationalism that focus on "the peripheral in the center," i.e., non-Western immigrants of the lower socio-economic classes in European and North-American settings, we focus on "the central in the periphery," i.e European and North-American academics who teach abroad, in a non-Western geography. ${ }^{5}$

\section{Cosmopolitans, transnationals, intellectuals}

The international academics in our research-occupational professionals or specialists in their fields-have options of different kinds. As Hannerz states:

the individuals involved with transnational cultures, are often in an advantageous position to make the choice. They have the time, during long stays or many of short duration, to explore another local culture, or several of them. Through contacts made by way of transnational cultures, they can find points of entry. Moreover, always knowing where the exit is, they need not to be anxious about preserving some comfortable sense of "at home." [1992:252]

Hannerz follows Konrad who describes

as transnational those intellectuals who are at home in the 
cultures of other peoples as well as their own. They keep track of what is happening in various places. They have special ties to those countries where they have lived, they have friends all over the world, they hop across the sea to discuss something with their colleagues; they fly to visit one another as easily as their counterparts two hundred years ago rode over to the next town to exchange ideas. [1984: 208-209]

The international academics in our research somewhat resemble the intellectuals in Konrad's observation in they way they described themselves with respect to their traveling experiences. A historian from the United States whom we call Karl, for example, portrayed a self-conscious, rational character who was in charge of his traveling experiences. "Probably people who travel are self-selected," he said. "What we found is what we have wanted." Goran, a Serb who defined himself as an "Oriental scholar," revealed rather cosmopolitan features by saying, "I am rather happy here but I could be happy anywhere." Nilay, a Turkish-American who was trained as a biologist and social worker, seemed to enjoy being in a different cultural setting, as she said, "I always liked meeting people and seeing different places." Her bicultural identity, she stated, has contributed to her interest in traveling. Norman, a political scientist from New Zealand, also described himself as a person who likes traveling as a lifestyle: "I like living in different locations, experiencing different cultures, meeting different people. I do like moving-the new experience. It is enjoyable. Location has changed me probably positively and I gained a lot from people being around discussing, drinking." In all cases, our informants seemed to have power over their choices, a position contrary to being either an adventurer or a drifter. They looked confident about their "points of entry" and "exit," and did not feel forced to be in motion, unlike some of their immigrant counterparts.

Having different kinds of contact with more than one country, that is, being a transnational, does not necessarily mean being a cosmopolitan. According to Hannerz "cosmopolitanism is first of all an orientation, a willingness to engage with the Other. It entails an intellectual and esthetic openness toward divergent cultural experiences, a search for contrasts rather than uniformity" (1996: 103). For him, if there are no locals, there are no cosmopolitans. In the light of this criterion for the assessment of cosmopolitanism, most of our informants would not be considered as cosmopolitans. Partly because of the relatively isolated location of the campus that we discuss below, they live in a "culturally encapsulated" area, 
which allows little contact with the city center and makes it hard for them to get involved with the local people. Thus their social interaction is limited to other international academics on campus. Moreover, although some of our informants were enthusiastic about "divergent cultural experiences" involving local people, some did not seem to be too eager to make the effort to meet with the local Other.

\section{Physical isolation, social exclusion, self-exclusion}

W hile recruiting particularly international staff, the University offers certain benefits, one of which is on-campus accommodation, which is situated in a suburban subdivision about 20 kilometers to the West of Ankara. For a newcomer, this offer is usually an incentive, at least in the beginning, due to the lack of access or lack of competence of the employee in an unfamiliar environment. However, in the long run, this advantage may turn out to be a quandary depending on various expectations of various individuals. On the one hand, on-campus housing hinders social contact with the locals (that is, the Other); on the other hand, it provides a "culturally encapsulated" protective environment in the form of a gated community. 6

The suburban subdivision within which the university campus is located and the university itself are "culturally encapsulated." Most people-local and foreigner alike-describe it as "modern" and "very Western" in style, which does not seem to look like the rest of the country. Our European and American respondents all commented, one way or another, on the similarities that they had observed between their homelands and the shopping malls, restaurants, cinemas, etc., that were part of the campus environment. Some explicitly spelled out the so-called "global culture" on campus. Some of the comments included a comparison of the physical environment, the climate and the topography. For example, "it's a lot like Los Angeles_-without water, slough, flat," said Emily, whose natal family now lived in southern California. And Marcus said, "the aridness of the mountains is very Australian, very timeless." But then he added what his first impressions were like when he first came to the campus: "the University was very European, I liked that." Neil's ("We are not really living in Turkey") and Norman's ("Here is more like the UK and the US") comments were similar as they pointed out the absence of "authenticity" or "Turkishness" on campus and the presence of a Western quality. 
Living abroad requires certain strategies in order to adapt to, to deal with, or to manage a different and new social and cultural environment. These strategies differ according to individual needs, expectations and preferences. The ones who are competent enough to establish a reasonable setting for their demands and expectations appear to be more satisfied with their experiences as a foreigner, and reduce the feeling of loneliness and isolation. We found in our research that living in a physically isolated setting did not necessarily bring a sense of social exclusion for our informants. For example, Norman, whose wife is a Turkish national, did not "feel excluded in Turkey-not socially excluded. I do not feel isolated, do not feel lonely, I feel at home. I am used to living in different contexts. I can adapt myself." Yet, he remarked that "there is not much interaction. It is something that I complain about to my wife." Goran, who was also married to a Turkish woman, did not feel socially excluded either. In fact, "Turkey is a land," according to him, "where to be a foreigner is not a bad thing." He was one of the few people in our sample who spoke fluent Turkish and who stressed the importance of having a good command of the local language for social inclusion: "If I do not have contact with the people, if I feel myself a stranger, if I did not understand the language and if I did not understand the news, it is social exclusion." His Turkish was an advantage for him: "Turks are very happy if foreigners speak their language. I do not have a feeling that I am a stranger." He was the most involved of our respondents in the local culture. "I feel unhappy when Istanbulspor (a local football team) loses the match," he said.

Reza, an architect and a theoretically-oriented intellectual, defines himself as an "urban" person, and isolation as "deprivation from cultural stimulation." For him, there was a paradox in the isolation of living in a culturally encapsulated area. "Everyone else seems to be isolated, so you do not feel isolated," he said. "A cultural no man's land . . a a culturally undefined, weak physical setting." Probably the most "cosmopolitan" of our respondents who was eager to encounter cultural differences, Reza does not consider language as an unexpected problem. "A traveler expects these problems: gets a map, a phrase book, and so on. These are the problems a traveler typically expects." Ironically, for precisely the same reasons (that is, the poor physical environment without cultural authenticity), Mahmoud feels extremely lonely: "zero social contact, too private, too very quiet, no interaction, almost complete isolation." It is ironic also because he has been in Turkey for nine years, the longest period among our informants, he had 
studied in Turkey, and he speaks Turkish in daily life. Emily, an elementary school teacher who has an active social life both in the international community and among Turkish residents, did not feel social exclusion although she did not speak Turkish "to speak of." She pointed out that foreigners on campus who feel excluded are in many cases self-excluding: "when you tell them to come over they don't come, they do not participate, and then they complain." She firmly states that "it depends on the foreigner to experience Turkey. They ask me how I am managing. How can it be difficult? Certainly everyone is helpful. They ask, "What about the language?' Everybody speaks English here!” According to Marcus, who teaches English and drama at the International School, social exclusion "comes up from time to time. It is not so much exclusion. It's identification of your differences.” He, as Emily, also underlined the role of self-exclusion: "It depends on how much you isolate yourself." Karl's experiences were more culture-based: "This is not my culture. I do not feel like I understand the culture but I do not feel Turks are excluding me." Overall, our respondents did not mention concerns about either social or physical exclusion, except self-exclusion. In other words, they explained exclusion in terms of personal choice.

Language is probably the most significant indicator of both the "cultural encapsulation"- - this Western/global quality-and the social exclusion of international academics, even though they do not necessarily identify this issue as a problem. Very few foreign academics and educators speak Turkish, yet language does not create a problem for communication on campus since most of the employees speak English. Off campus, however, they were all aware of their language isolation, although it does not have a disruptive effect on their daily lives.

\section{Where is home?}

$\prod$ he definition of the concept "home" varies from person to person. For transnationals who spend their lives on the move, there are many more criteria to include in a definition of home. Rapport and Dawson stated that these people, "through the continuity of movement make themselves at home; seeing themselves continually in stories, and continually telling the stories of their lives, people recount their lives to themselves and others as movement" (1998:33).

Most of our informants defined home in terms of their relationship with others, of sharing with and relating to others. For them,
Language is

probably the

most significant

indicator

of both the

"cultural

encapsulation"

-this Western/

global quality-

and the social

exclusion of

international

academics 
a similar background, a shared language, culture, or family were key factors in defining home. In this conceptualization, home is usually, but not always, a fixed place-a place where people are socialized and enculturated, and that they are attached to; they and their relations belong there. Some other people, however, define home in terms of "the self." They focus on becoming in the present ("to live fully in each moment"), on who they are and how they nurture themselves. For them, "home is a place for the soul" and "contemplative time need not be sought in special places or at special times." With such a definition in mind, they take home wherever they go. It is "a place where you'd be happy to be alone, where you'd be nurtured, stimulated - in short alive!" (Marcus 1995: 284-89).

Although the definitions of home as a place of sharing on the one hand, and as a part of the mobile self on the other, seem to be mutually exclusive, it is analytically hard to draw a line between these two conceptualizations. After all, people evolve, and transport their childhood homes and relations with them as a part of their selves, in their memories, fantasies, and actions. As Oliver Marc rhetorically asks, "are we perhaps on the verge of grasping that the environment is ourselves, for it has given us form, and that creation is nothing but a dialogue between the inside and outside?" (Marc 1977:80). Nevertheless, while some of the people we have talked to highlighted the relational nature of home, some of them highlighted the mobile, self-oriented nature.

Mahmoud was one of those informants who defined home in relational terms: "Social interaction makes a place home for me. When I find people to talk with, when my wife is here, I consider it home. When I am alone, . . . it is not home, but just a place to sleep." According to him, home "is a place where you live with ... family members." Helen, a graduate student who has come to Ankara as her husband's dependent, also stressed family as a key factor: "I'm emotionally attached to my parents and the United States. Family contact is the home first, then the United States in general." She missed celebrating Christmas with her parents for the first time last year. Although she is not alone in Ankara, being with her husband is not enough for her to feel at home. Reza, a short-term visiting professor in Ankara, was another person who defined home in terms of familial relations and emotional closeness. His case was more complicated, however, as his parents were from two different republics of the former Soviet Union. He had lived in Vienna with his parents, brothers and sisters, for about sixteen years, had his schooling there, and had become an Austrian 
citizen. And now he was a permanent resident of the United States, working as a university professor in Pittsburgh. He could not talk about one single home. "There is a sort of gradation," he said. "Still, the place that comes closest to home is Vienna," where he visits at least once a year, as there he lived "half of my conscious life" and his brother, sister and friends still live there.

For some, home is associated with permanence and control. "From the perspective of law, economics, and politics, the tenure status of housing, with its implications of personal control is the critical variable that defines "what makes a house home." However, this emphasis on tenure status ignores the large portion of the population-even in affluent countries like Switzerland-who choose to rent" (Lawrence 1987: 155). Probably because it implies some degree of permanence and some degree of personal control, house ownership is still the key for some people's definition of home. Nilay, is a second generation Turkish-American from Virginia who considered the USA her home. For her, a place she owned and had her own furniture, where she would be happy living for five or ten years, would be home. "Some place where I can choose, make life easy and convenient" she said. Ownership was not an important factor for others, however, especially when they were not happy with what they owned. Emily, another United States citizen grew up in the suburbs of southern California. After marriage, she had owned a house in rural Pennsylvania where she lived with her husband for five years, but "would never call Pennsylvania home." There she was working part-time, and was not happy. To her, Turkey, where she has lived less than two years, "is much more home than Pennsylvania." California could have been home, she commented, but "Californians move every two years." So did her parents, and she was "angry with them" as she did not have a "fixed place" for her to call home.

This notion of a fixed place, suggesting permanence, is a fairly common element in most definitions of home. Karl, for example had "no rooted fixed place to call home." He had to be "comfortable and long enough there to know" to call a place home, yet he had lived in three different states in the United States, and not longer than twelve years anywhere. Ankara and the university housing they were living in during our interviews "is home for us," he said, but they were leaving again for the States, where he was offered a better, tenure-track position.

"Home as control" emerged in our research as an important concept also at an individual, personal level. Privacy, at this level, turned out to be an important factor in our informants' conceptu- 
alization of home, albeit with different emphases. While the provision of privacy within the context of the immediate environment made a place home for some people, the lack of privacy within home was a definitive factor for others. Marcus, for example, had to be able to walk naked in his home and not worry whether the curtains were drawn. For Mahmoud, however, who defined home in terms of social interaction, everyone knows everyone else's business and "there is no need for privacy at home."

Two other responses, which defined home in relational terms, from Norman and Marcus, underlined "homeland" as home. Interestingly, both respondents were somewhat apologetic for still having emotional ties to their homelands. For Marcus, Darwin, Australia was home because of "the way of life" that he was used to. "This thing called culture that I can't really explain," connected him to Australia. "Just because I'm living overseas . . . I'm Australian no matter what." Norman had to think for a while to answer our question about where he considered home before he simply said, "I guess I still consider New Zealand home."

In the examples we have discussed so far, relations in a certain environment, whether in the past, present, or future, determined if a place was home or not. A certain length of time and a fixed place enabled knowing and establishing relationships, so that a home that was based on a relational definition could be founded either in the old country or in a new land. Mahmoud, for example, considered Ankara as a "second home," because he became "more foreigner in Bangladesh than here." Three of the people whom we had talked to, however (Neil, Nabil and Goran), were quite different in their formulations: they neither looked back to a certain home in the past, nor sought permanency. Their home was wherever they were.

"This is home," Neil said. "Where you live is home." He was born and raised in England, yet he was estranged: "My connections with home were not very tight." He had no binding family ties and he was disillusioned with the system in England. "I wanted to get away-to get away from the low esteem of teachers in the UK-escape; not looking for adventure." He had worked in Hong Kong for three years before coming to Turkey. At the time of our interview, he had been in Ankara for almost five years. Although Neil had no intention of moving back to the UK, at times he thought about England as home_-as an imagined home: "When I'm in England, this is home; when I am here, England is home." Moreover, "the States is also slowly becoming accepted as home now," because that's where his wife is from.

Nabil, an Iranian who had settled in the United States after the revolution, had been living in Turkey for about two years during 
the time of our research. He was one of those people who carried his home with him. "Anywhere I live is home" he said, and made a double-negative remark: "I do not feel not at home." Home was not a special concept for him. It was not permanent. He was not emotionally attached to any of the places he had lived in, including his parents' house in Iran where he had not lived as a child anyway. Until the age of 18 , he had lived in "company homes," which very much resembled the current university housing arrangement. Iran, his homeland, was not home either, because it had changed so much. Nabil knew, although he had not been back, that Iran was not the same place he had left. Living in London as a student was not any different: "A sense of being temporary," he maintained, whether he was in school, in graduate school, or in a particular job.

Goran, being a Serb from Sarajevo, Bosnia, had thought about the question of home before, and was very firm about where he stood in his conceptualization of home. "I am not typical," he said, "I have no strong feelings of home," and then he added: "I carry my home in my pocket." He considered his wife and daughter to be his family, with whom he had been living in Turkey for the last three years. Before coming to Turkey, he had lived in two different towns in Germany. He proudly said that he had no emotional connections to any place and that he was not homesick. "To be homesick means to be narrow in mind," he said. "Anybody who has something more in [his] head cannot be homesick. I don't think that people should die in the same place that they are born." Both Nabil and Goran came from homelands where turmoil and grave political changes were experienced. Their strong rejection of a concept of fixed homeland was probably not a coincidence. However when we suggested this connection, Goran disagreed. Even before the war he thought this way. He studied Persian, Arabic, and Turkish, "aiming to be an Indiana Jones." He cited a French priest who proposed a three stage evolutionary development for humanity. People in the first, most "primitive" stage had a concept of homeland. "Only stupid people love their homeland," he said. In the second evolutionary stage, "you carry your home in your pocket," he continued. In the third and final stage, "you don't feel at home anywhere-be a stranger everywhere." This idea of evolution towards homelessness resembles Konrad's idea of transnational intellectuals, albeit with a shift of emphasis toward those "who are at home in the cultures of other peoples as well as their own" (1984: 208-209). In a way, being at home anywhere and being at home nowhere are the same thing. 


\section{Conclusions}

V

arious perceptions and conceptualizations of "home" emerged from our study of expatriate academics and educators in a university campus located in Ankara. Our respondents, both men and women, who came from different cultures and academic disciplines and who had dissimilar definitions of home, showed a great diversity. While for some home meant homeland, others carried home in their pockets. Some highlighted permanence and control; some emphasized the relational nature of home; some defined home in terms of the self; yet others said that home was anywhere they lived. This diversity beyond pattern may indicate that unique personal histories and idiosyncratic attitudes are significant in these formulations. According to Clare Cooper Marcus, our attitudes toward home are largely shaped by our childhood experiences. "Either we mirror what we saw and experienced in our childhood home, or we react strongly against it" (1995: 82). Although our focus in this paper is not a psychological one, it is hard to omit psychological aspects all together when we talk about home. The unique personal histories and personalities of our informants, in conjunction with the vague concept called "cultural background," were indeed intimately linked to their conceptualizations of home.

Mobility probably takes a certain kind of personality. In a transnational context, where people leave the places they were born and raised in, and travel abroad, they identify themselves, at least, as adventurous: other places call them. Our respondents, with the exclusion of one person, either travelled for the adventure of experiencing different places, or escaped from home, because of a combination of social and personal reasons and wanted to establish home elsewhere. They defined themselves and their personalities as extroverted by using phrases such as "hyperactive," "adaptive," "friendly," "outgoing," and having a "good sense of humor." They were curious to see and experience more than what they were accustomed to. These people are possibly "philobats" or "domophobic," as British psychoanalyst Michael Balint classifies them, and not "ocnophils."

Being a transnational definitely requires new conceptualizations of what/where is home, and efforts to create the most favorable environment in order to cope with different cultural settings. Living in culturally encapsulated areas like gated communities or establishing one's own social networks are some of the survival strategies of transnationals. One's personality, background, percep- 
tions, expectations, abilities and social competence has a lot to do with the preferred type of strategies. The transnationals whom we have selected as the actors of our study do have similarities and differences with respect to their conceptions of what home is, what being a foreigner is, what isolation is, what social exclusion is, and finally what it is like living in a culturally encapsulated environment. Although answers to these questions vary from person to person, we observed a commonality among our informants with respect to their positive attitudes towards living in such a culturally encapsulated gated community. While some academics voiced their concern about their isolation from the "realities" of ordinary life outside the campus, most of them reported to be "comfortable" in the protected environment of this closed community. At this point, following Hannerz, we draw the line between transnationals and cosmopolitans.

Notwithstanding the class and social status differences between different groups of transnationals, seeking comfort in closed protected environments is analytically similar to the ghettoization tendencies of labor-migrants living in Europe. Academics in motion, in spite of their privileged position in their "host country" and relative freedom to travel around the world as a member of the "network society," are not all that different from migrant workers so far as their opting for social exclusion is concerned. Perhaps we should look elsewhere for socially inclusive transnational experiences or cosmopolitanism in practice.

\section{Notes}

${ }^{1}$ An earlier version of this paper was presented in XII aesop Congress: Community Based Planning and Development, Bergen, Norway 1999.

${ }^{2}$ The reader may be interested to know that the authors are Turkish women academics employed by the same University after having had similar transnational experiences in Europe and the United States. They both have multi-disciplinary educational background and training in sociocultural anthropology. While Tandoğan received her first degree in political science, İncirlioğlu was trained as an architect.

${ }^{3}$ The International School, also located on campus, provides $\mathrm{K}-12$ education for both foreign and Turkish children.

${ }^{4}$ For a summary of basic information concerning these eleven informants see Tables 1 and 2 in the Appendix.

${ }^{5}$ At this point, one might ask why Turkey is part of the periphery and why it is non-Western. As it will be apparent further in the text, several informants have argued that there were many similarities between their countries in Europe and the United States on the one hand, and Turkey on the other. Although it is beyond the scope of this article, it would be worth- 
while to rethink these categories in both historical, geopolitical context and in the age of globalization, with the concept of class structure in mind.

${ }^{6}$ There is nothing unique about Ankara that produces these "encapsulated gated communities," as different kinds of gated communities have been mushrooming in the major metropolises in Turkey, including Istanbul and Izmir.

${ }^{7} \mathrm{~A}$ philobat is "a person who enjoys innovation and ambiguity, who seeks out activities involving a temporary loss of equilibrium . . . and for whom objects—both human and physical — may sometimes be seen to be getting in the way" (Marcus 1995: 91). Domophobics are those people who have a fear of staying in any one place long enough to feel at home, possibly because of too many unresolved emotional issues from childhood (Marcus 1995: 92). An ocnophil, however, is a person who clings to familiarity and to secure places and people, shuns unpredictable or thrill-seeking experiences, and cherishes objects, both human and physical (Marcus 1995: 91).

\section{References Cited}

Blumenstyk, Goldie.

1995 A Failed Venture. The Chronicle of Higher Education 30: A26-28.

Goyen, William.

1947 The House of Breath. New York: Penguin Books.

Hannerz, Ulf

1992 Cultural Complexity. New York: Columbia University Press.

Johnson, Todd M.

1991 Wages, Benefits, and the Promotion Process for Chinese University Faculty. China Quarterly $125: 137-155$.

Konrad, George.

1984 Antipolitics. San Diego and New York: Harcourt Brace Jovanovich.

Lawrence, Roderick J.

1987 What Makes a House Home? Environment and Behavior, 19 (2): 154-168.

Marc, Oliver

1977 Psychology of the House. London: Thames and Hudson.

Marcus, Clare Cooper.

1995 House as a Mirror of Self. Exploring the Deeper Meaning of Home. Berkeley: Conari Press.

Olwig, Karen Fog.

1997 Cultural Sites: sustaining a home in a deterritorialized world. In Siting Culture: The Shifting Anthropological Object. Kirstin Hastrup and Karen Fog Olwig, eds. Pp. 17-39. London and New York, Routledge. 
Rapport, Nigel, and Andrew Dawson.

1998 Migrants of Identity. Oxford and New York: Berg.

Schiller, Nina Glick, Linda Basch and Cristina Szanton Blanc

1992 Towards a Definition of Transnationalism. In Towards a

Transnational Perspective on Migration. N. G. Schiller, L. Basch and C. Szanton Blanc, eds. Pp.1-24. New York: The New York Academy of Sciences.

Tekeli, Ilhan.

1998 Türkiye'nin Konut Politikaları Üzerine. (On Turkish Housing Politics). Arredamento Mimarlik (3): 70-73.

Vertovec, Steven

1999 Conceiving and Researching Transnationalism. Ethnic and Racial Studies 22 (2): 447- 462.

Appendix

Table 1: Informants: Background Information

\begin{tabular}{|c|c|c|c|c|c|c|}
\hline Pseudonym & Origin & Age & Sex & $\begin{array}{c}\text { Marital } \\
\text { Status } \\
\end{array}$ & Occupation & Area of Specialization \\
\hline NORMAN & New Zealand & 33 & $M$ & M & instructor & political science \\
\hline MARCUS & Australia & 31 & M & $S$ & teacher & English, theatre \\
\hline LARRY & U.K. & 32 & M & $M$ & teacher & science \\
\hline MAHMOUD & Bangladesh & 30 & M & M & res.assist. & urban design \\
\hline NILAY & USA (Turkish) & 31 & $\mathrm{~F}$ & $S$ & instructor & biology; social work \\
\hline NABIL & USA (Iran) & 38 & M & M & instructor & political science \\
\hline HELEN & USA & 32 & $\mathrm{~F}$ & $M$ & graduate student & history \\
\hline KARL & USA & 34 & M & $M$ & instructor & history \\
\hline EMILY & USA & 33 & $\mathrm{~F}$ & $M$ & teacher & primary school \\
\hline REZA & $\begin{array}{l}\text { Austria/USA } \\
\text { (formerUSSR) }\end{array}$ & - & M & $S$ & visiting prof. & architecture \\
\hline GORAN & Bosnia (Serbian) & 38 & M & M & instructor & oriental scholar \\
\hline
\end{tabular}


City \& Society

Table 2: Informants: Residence in Turkey

\begin{tabular}{|l|l|l|l|c|c|}
\hline Pseudonym & $\begin{array}{c}\text { Residence } \\
\text { duration }\end{array}$ & $\begin{array}{c}\text { Purpose of } \\
\text { stay }\end{array}$ & $\begin{array}{c}\text { On-campus } \\
\text { duration }\end{array}$ & $\begin{array}{c}\text { Household } \\
\text { size }\end{array}$ & $\begin{array}{c}\text { Number } \\
\text { of Rooms }\end{array}$ \\
\hline NORMAN & $>1$ year & marriage & $>$ year & 2 & 2 \\
\hline MARCUS & $>1$ year & work & $>$ year & 1 & 2 \\
\hline LARRY & 5 years & work & 1 year & 2 & 3 \\
\hline MAHMOUD & 9 years & education & 1 year & 2 & 2 \\
\hline NILAY & 3 years & work & 3 years & 1 & 2 \\
\hline NABIL & 2 years & marriage & 2 years & 2 & 2 \\
\hline HELEN & 2 years & research & 2 years & 2 & 2 \\
\hline KARL & 2 years & work & 2 years & 2 & 3 \\
\hline EMILY & 2 years & marriage & 2 years & 2 & 3 \\
\hline REZA & 2 months & work & 2 months & 1 & 2 \\
\hline GORAN & 3 years & marriage & 3 years & 3 & 2 \\
\hline
\end{tabular}

